\title{
HOW TO PROMOTE UNIVERSITY STUDENTS' CRITICAL THINKING
}

\author{
Mkhitaryan Y.S., PhD, Professor \\ Faculty of Foreign Languages, Khachatur Abovian Armenian State Pedagogical University, \\ Armenia, Yerevan
}

DOI: https://doi.org/10.31435/rsglobal_ws/12072018/5998

\begin{abstract}
ARTICLE INFO
Received: 16 May 2018

Accepted: 23 June 2018

Published: 12 July 2018

\section{KEYWORDS}

critical thinking, university students, survey,

Armenian educational system, strategy, theoretical class.

ABSTRACT

Promoting students' critical thinking in Armenian universities is not an easy task and this can be explained historically. In the past it was not a usual practice for students to challenge the views of professors, lectures being usually taken without retorting or questioning. Though some radical changes have taken place in the Armenian educational system during the last two or three decades, the old tradition is still preserved in some national universities. The aim of the present paper is to show what strategies can be applied to promote university students' critical thinking, particularly in theoretical classes. The strategies chosen for this purpose include: psychological preparation, stimulating interest, identifying the problem, suggesting related sources, evaluating the problem indirectly, solving the problem independently, making cross-linguistic references, mastering scientific language register. A survey was conducted to assess the level of the students' critical thinking during Theoretical English Grammar Course. The results show that out of 34 students involved in the survey only $35 \%$ could actually display critical thinking ability, the rest making tentative, probing steps only.
\end{abstract}

Citation: Mkhitaryan Y. S. (2018) How to Promote University Students' Critical Thinking. World Science. 7(35), Vol.1. doi: 10.31435/rsglobal_ws/12072018/5998

Copyright: (C) 2018 Mkhitaryan Y.S. This is an open-access article distributed under the terms of the Creative Commons Attribution License (CC BY). The use, distribution or reproduction in other forums is permitted, provided the original author(s) or licensor are credited and that the original publication in this journal is cited, in accordance with accepted academic practice. No use, distribution or reproduction is permitted which does not comply with these terms.

Introduction. In the recent decades there has been a change in the educational systems of many countries from a focus on providing knowledge to an emphasis on developing critical thinking skills. It has been recognized that one of the basic aims of education, especially at the university level is to develop students' ability to think independently, using judgment and reasoning in expressing their own opinions and views. As B. Trilling and D. Fadel note, "critical thinking is a high priority outcome of higher education which will help students solve many problems they face in both their professional and personal lives" [1,107]. However, there seems to be little unanimity about what is meant by the very term, how it should be done, and how to foster this ability in students. Educators agree that in keeping up with the ever-changing technological advances, students will need to obtain, understand, and analyze information on a much more efficient scale and it is our job as educators to equip our students with the strategies and skills they need to think critically in order to cope with these problems and obstacles they face [2].

\section{Critical thinking in education}

\subsection{The notion of critical thinking}

Among the many definitions of the term 'critical thinking' suggested by different linguists we find it proper to accept the definition of this concept suggested by M. Weimer: "Critical thinking can include the thinker's dispositions and orientations; a range of specific analytical, evaluative, and problem-solving skills; contextual influences; use of multiple perspectives; awareness of one's own 
assumptions; capacities for metacognition; or a specific set of thinking processes or tasks" [3, 127]. A recent article in The Teaching Professor [4] highlighted the variation in definitions for critical thinking. The authors point out that critical thinking is either thought of generally or as being discipline- specific. They cite research that critical thinking is probably a combination of both. As a multidimensional construct, it contains some general reasoning skills and some skills that are specific to the discipline. So we can conclude that it is impossible to develop critical thinking in students if we cannot understand what is meant to be a critical thinker in a particular discipline. Despite a great number of recent publications in this field there are few research works concerning the development of critical thinking skills, particularly in classes on theoretical courses. Many university textbooks present information to enlarge the scope of students' knowledge on the subject, however, few special exercises are provided to enhance students' independent thinking [See: $5 ; 6 ; 7]$.

\subsection{The Armenian educational system (a brief historical review)}

The unfavorable situation as regards the development of independent thinking in university students is characteristic of the Armenian educational institutions as well. This can be explained from the historical perspective. As a constituent part of the Soviet Union, Armenia had to adopt the overall educational system (both pedagogical and instructional) without much criticism. The teaching was generally teacher-centered and learning process was largely based on mechanical memorization. What was written in books and textbooks was expected to be taken without questioning. This was most explicitly expressed in the period of the so-called 'personality cult,' which permeated every sphere of soviet life, including the educational system. Not only were students deprived to speak out independently but they were imposed almost forcibly to adopt party ideologists' opinions and views. After the demise of the Soviet Union Armenia has become an independent state and has to exist on its own and like many post-Soviet republics was involved in the universal process of globalization and internationalization. In 2005 Armenia became a full member of the Bologna Process, which meant implementing a number of reforms in the educational system. The reforms focus on establishing international cooperation and offer broad access to high-quality education, based on democratic principles and academic freedom [8, 254]. As a result new teaching techniques and grading systems were adopted, special funds were made available for student and scholar exchange programs. Professors and instructors find it necessary to evaluate not only students' knowledge, but their active participation in the classroom. As D. Halpern says, "Students feel more emancipated and independent, expressing their ideas and views openly and freely" $[9,210]$. However, the old attitude is still preserved in some Armenian universities, especially in theoretical classes.

The aim of the present paper is to show what strategies could be used to promote critical thinking in students taking a specialist theoretical course. I have chosen a course of Theoretical English Grammar as one of the theoretical courses I deliver at the faculty of Foreign Languages, ASPU. The subject is rather difficult since the field requires not only a deep knowledge of both practical and theoretical grammar, but also the ability to analyze and synthesize information.

\section{Strategies for promoting students' critical thinking}

We have examined a number of researches on the use of strategies for promoting student critical thinking both at high school and university levels $[10 ; 2 ; 11 ; 4 ; 12]$ and on the basis of this study we suggest our own list of strategies recommended specially for Armenian students. We have chosen theoretical classes since it is here that the problem is most urgent and almost not investigated by Armenian linguists and educators. The respondents comprise 34 students of the faculty of foreign languages at Armenian State Pedagogical University who major in the English language and take a course in Theoretical English Grammar. We should point out the fact that the majority of this contingent come from rural regions where schools are poorly-equipped technologically and are in a great need of good teachers, including teachers of English. This adds to the difficulty of enhancing critical thinking in these students since they are not taught to think independently even in their native language. Naturally, this makes our work still more difficult and time-assuming but we never lose heart or give up.

We suggest eight steps for critical thinking instruction which include: 1) psychological preparation, 2) stimulating interest, 3) identifying the problem, 4) suggesting relevant resources, 5) evaluating the problem indirectly, 6) solving the problem independently, 7) making cross-linguistic references, 8) using scientific writing register. We will consider each strategy in detail.

\subsection{Psychological preparation}

This activity is very important for Armenian university students since it will help them overcome embarrassment and anxiety when challenged to express themselves independently. To instill confidence and self-assurance in students, we provide them with 3 Three Gold Rules for Successful Critical Thinking suggested by A. Manning: a) be rational, b) be open-minded, c) be radical [13]. What 
the author means is that students should follow their reason, broaden their perspectives and, most importantly, should not be afraid of challenging what experts and scholars have written about a particular topic. After all, as Manning says, the ideas of Darwin and Einstein were once ridiculed. On our part, we can add that such a well-known linguist as N. Chomsky revised some of his ideas, even rejected them later.

\subsection{Stimulating interest}

On the very first day of meeting with the respective students the lecturer should make clear that their class is going to be solely interactive. He will not have students just sitting in class and listening to lectures passively. They are expected to participate in class by asking questions and expressing their views on items pertaining to the subject of the lecture. Thus professors can create ground for students' active involvement in the class. The professor can trigger students' interest by rewarding them. For example, he/she can announce that students who do independent work by expressing new and original ideas, or volunteer to write a report on some controversial theoretical topic will get extra credit. In general, in giving grades and scores an instructor is expected to evaluate the level of independent work done by the student. This may also include students' participation in student conferences organized home and abroad and writing articles for publication. All this can be a good way to stimulate students' interest in working and thinking independently.

\subsection{Identifying the problem}

Every subject offers opportunities for critical thinking. The professor can always find a good deal of time for free discussion so that each student will have an opportunity to participate in it. It is essential that the topic chosen could best serve the goals in developing student critical thinking. For this purpose students are instructed to deal with a specific problem of controversial nature. To be more exact, the students are assumed to show their personal opinion concerning some grammatical issue that is of arguable character. The case in point may be N. Chomsky's thesis according to which grammar is independent of meaning [14], a statement that has caused much debate in the linguistic community. Students were instructed to express their opinion concerning the linguist's statement about the grammaticality vs meaning of the 'famous' sentence Colorless green ideas sleep furiously and its invalid version Furiously sleep ideas green colorless. As is known, Chomsky asserts that though both the sentences are meaningless, the first sentence is grammatical whereas the second sentence is not. Students are instructed to decide whether they agree or disagree with this view.

\subsection{Suggesting related data}

Students cannot think critically if they do not have the information they need. If necessary, we provide students with resource materials pertinent to the subject of discussion. They should be of multiple and diverse character so that to enable students to consider the issue from different perspectives. When investigating the suggested data, the students should focus on why and how, not just what, when and where points since only in this case it will be possible for them to treat the issue analytically and comprehensively. The resources suggested for the aforementioned topic may include the following works $[15 ; 16 ; 17 ; 18 ; 19$, etc.]. Of special importance are those researches which criticize Chomsky's approach on the issue. In this respect we find it reasonable to suggest J.W. Oller's article "On the Relation between Syntax, Semantics, Pragmatics" [18]. As is known, the author critiques Chomsky for treating grammar as independent of meaning by asserting that the sentence Colourless green ideas sleep furiously is not only grammatical, but may also be perceived as meaningful. J. O J. Oller says, "With a bit of imagination, we can supply an interpretation for it, like "Insipid immature ideas lie dormant in a state of potential explosiveness". Getting acquainted with the recommended literature, especially those of critical character students will find it easier to discuss the item under question. Students are not assumed to confine themselves to the recommended sources. They can seek additional sources on their own. Online sources may be of great help too and students can benefit largely from them.

\subsection{Evaluating the problem indirectly}

Naturally we cannot expect the students to offer any substantial critical comment on the outstanding linguist's theory. To help students recognize and overcome the difficulty, we ask students to consider the problem from other linguists' points of view, encourage students to get familiar with other interpretations. Having investigated the literature on the topic and getting acquainted with different approaches concerning the issue, the students can consider it from two opposing perspectives: one of Chomsky's and the other of Oller's (or some other linguist's) point of view. As the survey showed the students (34) were not unanimous in their opinions. They divide in two groups: the first group (12 students) adhered to Chomsky's approach, while the other group (22 students) supported Oller's position. Let them each present the issue from the point of the mentioned scholars' views. The presentation can be performed by means of roleplaying. Roleplaying has always been considered an 
excellent method for exercising critical thinking. It involves the conflicting groups and each group (or representative of the group) has to answer the questions put forward by the opposite group. The answers are supposed to include the reasoning and argumentation made by the opposing linguists themselves provided students have fully assimilated the latter's positions. It is necessary to involve in the discussion as many students as possible. Presenting the topic by the method of roleplaying gives students an opportunity to examine the issue from different perspectives, which can widen the students' academic horizon and help them better understand and digest the theoretical material. As S. Franciosi says, "Collaboration among students adds rigor to the categorization, making the final result more robust" $[20,29)$. This strategy repeated over time can cultivate a habit of independent thinking in students and they will begin to see critical thinking as part of classroom activity and more and more students would like to be involved in the process. Following this strategy we can suggest a list of topics which engender a good deal of controversy in linguistic literature.

\subsection{Evaluating the problem independently}

We suppose it is the most important part of the process of critical thinking when students express their independent opinions in regard to the suggested issue. Now that they got familiar with the techniques of expressing controversial ideas it will become easier for students to display critical thinking skills. Understandably, we cannot expect all the students of the group manifest independent thinking, but even a few active participants can revive the class making it interesting and less stressful. Using their own reasoning and argumentation students try to discuss the issue from their perception of the problem, not being fully influenced by the approaches of the linguists discussed before. As A. Radford says, "Soon Chomsky will disparage and disregard it, but within limits it still works remarkably well" [15]. All this testifies to the fact that both views expressed by the students are to be accepted with more or less degree of validity.

A higher order of independent thinking may involve issues which have not been special objects of linguistic discussion or study before.

\subsection{Making cross-linguistic references}

Students can be instructed to view the same grammatical phenomenon in two languages: English and their native language (Armenian) or another foreign language they know. It is another chance for the students to manifest their critical thinking skills. We may give the students an opportunity in choosing topics for discussion themselves so that they can exhibit their own interests and preferences. If they are at difficulty we can help them by giving hints. When discussing Fillmore's Case Theory we can ask the students to make references to the theory of case in the Armenian language. There has been a long-standing debate among the Armenian linguists as to the number of functional cases (5 or 7) taught in Armenian high school. The students are expected to decide which case system (the 5-case or 7-case system) should be taught in high school. Students can also discuss to what extent Fillmore's Case Theory may contribute to the solution of this problem or the choice between 5-case and 7-case systems in the Armenian language. This implies a lot of independent work and will actually promote critical thinking.

Students will need to look closely at the issue in each compared language and as a result this may lead them to discover some linguistic facts that have never been observed by them in their own language before. According to Linda Elder and Richard Paul, authors of "Critical Thinking Development: A Stage Theory, students who know how to analyze and critique ideas are able to make connections across disciplines, see knowledge as useful and applicable to daily life and understand content on a deeper, more lasting level [12]. By giving students chances to express their independent views on the suggested issues within their discipline, we enhance confidence in their ability to do independent research work and later participate in degree programs for obtaining a scientific degree.

\subsection{Mastering scientific language register}

One of the requirements of scientific language is to express views and opinions in a precise and unambiguous manner which can be provided by the appropriate choice of grammatical structures and vocabulary. However, it is clear that any research data have a degree of uncertainty, doubt and this fact should be taken into consideration when presenting them. In other words, it is recommended that students should use hedges to make their speech less assertive and categorical. As Th. Payne notes, "hedging adverbs protect the speaker from possible charges of uttering false information" [21, 74]. It is essential for university students since they are doing their first, probing steps in science and naturally their opinions and standpoints lack certainty and precision. Students are supposed to express their hesitancy and lack of confidence by using hedges, words which make statements less authoritarian. It is especially important for Armenian students who are accustomed to reading Armenian texts in which hedges are relatively few compared with English texts [22, 2010]. Students should recognize hedging as an inherent part of scientific language style. As A. Crismore and R. Farnsworth note, "hedging is a 
mark of a professional scientist, one who acknowledges the caution with which s/he does and writes on science" $[23,135]$. When grading a student's work the professor or instructor should take into consideration the use of hedging in their written and oral discourse as well.

Results of investigation.

3. Survey

The aim of this survey is to investigate the students' level of ability to think critically. As a material for discussion we have chosen an extract from N. Chomsky's work "The Independence of Grammar" ("Syntactic Structures"). As a controversial view we have taken the work by J. W. Oller, Jr. "On the Relations between Syntax, Semantics, Pragmatics". The survey includes questions requiring students' linguistic competence, analytical mind, rationality, open-mindedness, independent and critical thinking. In consists of 5 activities each aimed at displaying a certain level of critical thinking. The assessing was performed on the basis of two seminars on the aforementioned topic.

\section{Activity 1. Understanding the text}

1. How does N. Chomsky define language? sentence?

2. How does the linguist define the notions of grammaticality and ungrammaticality of the

3. What examples does the author adduce to illustrate his point of view?

4. What does the author mean by "high order of statistical approximation of English"?

5. How does the linguist conclude the text?

\section{Activity 2. Identifying the problem}

1. What is controversial in N. Chomsky's statement concerning the independence of syntax?

2. Do you think the argument put forward by N. Chomsky is sufficient?

3. Are you acquainted with other sources related to the topic/?

4. What is N. Oller's approach to the issue?

5 . Which is the best way to deal with the problem?

Activity 3. Evaluating the problem indirectly

1 . Which is the basic point of N. Chomsky's theory?

2. What is J. Oller's main argument against Chomsky's thesis?

3 . Do the examples adduced by J. Oller illustrate his reasoning?

4. Which is the weak point of J. Oller's approach?

5 . Which theory do you find more scientifically-grounded? Why?

\section{Activity 4. Evaluating the problem critically}

1. Do you completely accept N. Chomsky's reasoning and argumentation concerning the theory of independence of syntax? Why?

2. Do you think the examples adduced by N. Chomsky are sufficient to prove his thesis?

3 . What is the rationale behind J. Oller's critique of N. Chomsky's theory?

4. What argumentation would you apply to accept or reject N. Oller's thesis?

5 . What examples of your own can you adduce to support your point of view?

Activity 5. Making cross-linguistic references

1. Which Armenian linguists wrote on N. Chomsky's syntactic theories?

2. What is the prevailing approach among Armenian linguists as to the relation between syntax and meaning?

3. Which of them supported N. Chomsky's theory of independence of syntax?

4. Do you find their reasoning convincing?

5. What argument is applied to support the opposite view? Is it analogous with N. J. Oller's approach to the issue?

Table 1 . The results of the survey can be presented by the following diagram:

\begin{tabular}{|c|c|c|}
\hline N of activity & $\begin{array}{c}\text { The number of students giving } \\
\text { the right answers }\end{array}$ & Percentage \\
\hline Activity 1 & 30 & $88,2 \%$ \\
\hline Activity 2 & 26 & $76,4 \%$ \\
\hline Activity 3 & 22 & $64,7 \%$ \\
\hline Activity 4 & 12 & $35,2 \%$ \\
\hline Activity 5 & 11 & $32,3 \%$ \\
\hline
\end{tabular}




\section{Findings.}

Finding 1: The majority of the students (88\%) could answer the questions on the text correctly, showing the understanding of the linguistic text and as well as language competence; 4 students fail because of the lack of sufficient knowledge of the foreign language.

Finding 2: The students $(76 \%)$ could easily reproduce the other linguists' views and approaches, using the latter's argumentation and reasoning but failed in expressing their independent perception of the problem.

Finding 3: The $64 \%$ students could analyze and evaluate the material with some argumentation and evidence but not sufficient to show higher-order thinking.

Finding 4: The ability to think critically which is reflected in problem-solving and making cross-linguistic references was demonstrated by about $35 \%$ of the total number. The other students show a lack of critical and creative thinking.

Conclusions. Summing up the study we can say that promoting students' critical thinking in Armenian universities is fraught with some difficulty, which can be explained historically. To overcome this difficulty the paper presents eight strategies which are supposed to develop students' critical thinking in theoretical class: psychological preparation, stimulating interest, identifying the problem, suggesting related sources, evaluating the problem indirectly, solving the problem independently, making cross-linguistic references, mastering scientific language register. But as the survey shows it is not an easy task: out of 34 students involved in the survey only $35 \%$ could actually display a real critical thinking ability, the rest making tentative, probing steps in this regard. We think implementing the aforementioned strategies regularly and efficiently may eventually lead to overall success.

\section{REFERENCES}

1. Trilling B. and C. Fadel (2009) 21 century skills: Learning for life in our times. John Wiley \& Sons.

2. Cox J. (2016) Teaching Strategies to Promote Critical Thinking </www.teachhub.com/teaching-strategiespromote-critical-thinking>

3. Weimer $\mathbf{M}^{1}$ (2013) Assessing Critical Thinking Skills. The George Washington GSEHD Home > Art. New Jersey: Ablex, Norwood >

4. Weimer $\mathbf{M}^{2}$. (2013) Critical Thinking: Definitions and Assessments. https://www.facultyfocus.com

5. Blokh M.T. Semionova, S. Timofeyeva (2004) Theoretical English Grammar. Seminars. Moscow: Visshaya Shkola.

6. Scott F.S., C.C. Bowley, C.S. Brockett, J.G. Brown, P.R. Goddard (1980) English Grammar. A Linguistic Study of its Classes and Structures. London: Fakenham Press Limited.

7. Mkhitaryan Y.and A.Cubaryan (2013) Theoretical English Grammar. Yerevan: YSU Press.

8. Keshishian F. (2013) Culture and Classroom Communication:A Pilot Study in the Post-Soviet Republic of Armenia. Journal of Intercultural Communication Research. pp.252-274.

9. Halpern D. (1996) How to promote student reflection and critical thinking <www.hawail. ed/...>

10. Eldridge G. (2010) Enhancing Critical Thinking for All Students. Online Articles <http://...in two elements of algebra for all students.

11. Crockett L.W. (2017) 12 Strong Strategies for Effectively Teaching Critical Thinking Skills.https://globaldigitalcitizen.org.

12. Elder L. and R. Paul (2010) Critical Thinking Development: A Stage Theory www.criticalthinking.org.

13. Manning A. (2008) English for Language and Linguistics in Higher Education Studies https://www.garneteducation.com/app/uploads/2014/12/ESAP-Lang-and-Ling-TB2

14. Chomsky and his critics: <www nybooks.com/articles1980>

15. Radford A. (1988) Transformational Grammar: A First Course. Cambridge: Cambridge University Press.

16. Lyons J. (1971) Introduction to Theoretical Linguistics. Cambridge University Press.

17. Bornstein D. (1984) An Introduction to Transformational Grammar. Lanham:University Press of America.

18. Oller, Jr. J.W. (1977) On the Relation between Syntax, Semantics, Pragmatics. $<$ https://www.researchgate.net/publication/249932491

19. Jahn M. (2002) "Colorless green ideas sleep furiously": A Linguistic Test Case and Its Appropriations < www.uni-koeln.de/ ame02/jahn>

20. Franciosi S. (2014) Teaching Students to Categorize TOEFL Essay Topics // English Teaching, FORUM, vol 52, No4, pp. 28-35.

21. Payne Th.E. (2011) Understanding English Grammar. Cambridge University Press.

22. Mkhitaryan Y.and S. Tumanyan (2014) On Differences in the Use of Hedges in English and Armenian Academic Discourse. // Social and Behavioral Sciences. Elsevier Ltd. pp 2006-2011

23. Crismore A. and R. Farnsworth (1990) Metadiscourse in popular and professional science discourse// Writing Scholar. Studies in Academic Discourse ed. by W. Nash, Newbury Park, Ca.Sage. 